\title{
Suplementação com ácido linoléico conjugado: estabilidade oxidativa dos suplementos e correlações com conteúdo dos lípides totais hepáticos e indicadores da oxidação dos lípides biológicos de ratos Wistar ${ }^{1}$
}

\author{
Conjugated linoleic acid supplementation: oxidative \\ stability of supplements and correlations with total \\ hepatic lipid contents and biological lipid \\ oxidation indicators in Wistar rats
}

Lilia Ferreira SANTOS-ZAGO2

Adriana Prais BOTELHO3

Admar Costa de OLIVEIRA³ (in memoriam)

RE S U M O

\section{Objetivo}

O objetivo do trabalho foi avaliar a estabilidade oxidativa de misturas comerciais de ácido linoléico conjugado e buscar possível correlação entre a suplementação e o conteúdo total de lípides hepáticos, e também de alguns indicadores da oxidação lipídica em ratos.

\section{Métodos}

Um ensaio biológico com 30 ratos divididos em três grupos $(n=10)$ caracterizando os grupos controle e suplementados com as misturas comerciais AdvantEdge ${ }^{\circledR}$ e One ${ }^{\circledR}$ foi realizado. A concentração administrada foi de $2 \%$ em relação ao consumo de dieta e os animais foram suplementados durante 42 dias. O conteúdo total de lípides do fígado foi determinado e a morfologia do órgão foi examinada por meio de microscopia

\footnotetext{
1 Artigo elaborado a partir do Projeto de Pesquisa intitulado "A suplementação com ácido linoléico conjugado e o perfil lipídico, composição corporal e peroxidação lipídica em ratos”. Apoio: Fundação de Amparo à Pesquisa do Estado de São Paulo (Processo 2003/07648-4) e desenvolvido no Departamento de Alimentos e Nutrição da Faculdade de Engenharia de Alimentos da Universidade Estadual de Campinas.

2 Pontifícia Universidade Católica de Campinas, Centro de Ciências da Vida, Faculdade de Nutrição. Av. John Boyd Dunlop, s/n., Jd. Ipaussurama, 13060-904, Campinas, SP, Brasil. Correspondência para/Correspondence to: L.F. SANTOS-ZAGO. E-mail: <lzago@fea.unicamp.br>.

${ }^{3}$ Universidade Estadual de Campinas, Faculdade de Engenharia de Alimentos, Departamento de Alimentos e Nutrição, Programa de Doutorado em Alimentos e Nutrição. Campinas, SP, Brasil.
} 
ótica. Índice de peróxido e malondialdeído foram determinados para avaliar a estabilidade oxidativa dos suplementos in vitro. Índice de peróxido, malondialdeído, 8-iso-PGF ${ }_{2 \alpha}$ isoprostana e catalase foram determinados como indicadores da oxidação dos lípides biológicos.

\section{Resultados}

Os resultados demonstraram baixa estabilidade das misturas comerciais à oxidação in vitro. As associações entre o consumo de ácido linoléico conjugado e malondialdeído $(r=-0,7914, p<0,0001)$ e catalase $(r=-0,5991, p=0,008)$ foram moderadas, negativas e significantes, demonstrando que o ácido linoléico conjugado reduziu a oxidação lipídica in vivo. O conteúdo dos lípides totais hepáticos não aumentou $(22,42 \%$, DP=1,40\%) e a morfologia do órgão permaneceu íntegra.

\section{Conclusão}

Embora esse protocolo de suplementação com ácido linoléico conjugado tenha reduzido a oxidação lipídica,

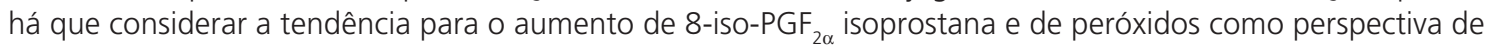
continuidade das pesquisas sobre a reinvestigação do efeito antioxidante do ácido linoléico conjugado.

Termos de indexação: Ácidos linoléicos conjugados. Estresse oxidativo. Lípides.

\section{A B S T R A C T}

\section{Objective}

The claimed action of conjugated linoleic acid as an antioxidant is unexpected and unclear, in view of its chemical structure - a conjugated diene, i.e., a fatty acid in its initial stage of autoxidation. Indeed, it can be speculated that it could act as a pro-oxidant, increasing oxidative stress in biological systems, nevertheless it has carbon-carbon bonds in the trans configuration.

The objective of the present work was to evaluate the oxidative stability of commercial mixtures, and to investigate a possible correlation between conjugated linoleic acid supplementation and total hepatic lipid content, as well as some lipid oxidation indicators in rats.

\section{Methods}

A biological assay was done with thirty rats divided into three groups $(n=10)$ characterized as control and supplemented with the commercial mixtures AdvantEdge ${ }^{\circledR}$ and One ${ }^{\circledR}$. The mixtures were administered in the concentration of $2 \%$ of the total diet consumption, and animals were supplemented for 42 days. The total liver lipid content was determined, and the morphology of the organ was examined by optical microscopy. Peroxide and malondialdehyde indexes were determined in vitro in order to evaluate the oxidative stability of the supplements. Peroxide, malondialdehyde and 8-iso-PGF ${ }_{2 \alpha}$ isoprostane and catalase were determined as biological lipid oxidation indicators.

\section{Results}

Results indicated a low in vitro oxidation stability of commercial mixtures. Associations between conjugated linoleic acid consumption and malondialdehyde $(r=-0.7914, p<0.0001)$, and catalase $(r=-0.5991, p=0.008)$ were moderate, negative and significant, demonstrating that conjugated linoleic acid reduced in vivo lipid oxidation. Total hepatic lipid content did not increase $(22.42 \%,(S D=1.40 \%)$, and the organ remained morphologically undamaged.

\section{Conclusion}

However, even though this CLA supplementation protocol did reduce lipid oxidation, a tendency was observed to an increase of 8-iso-PGF2 alpha isoprostane and peroxides induced by conjugated linoleic acid. Further research may be needed to verify its antioxidant effect.

Indexing terms: Linoleic acid, conjugated. Oxidative stress. Lipids.

\section{N T R O D U ÇÃ O}

O efeito do ácido linoléico conjugado (CLA) sobre o processo de autoxidação lipídica tem sido bastante pesquisado nos últimos anos, com resultados ambíguos, os quais não permitem ainda conclusões claras a respeito da sua atuação como agente antioxidante. A presença de ligações 
duplas na configuração trans em isômeros do CLA contribui para a estabilidade do mesmo à oxidação. No entanto, ao levar em consideração o fato de que a conjugação das duplas ligações é um dos primeiros passos da autoxidação lipídica, e que a partir daí se iniciam as irrefreáveis reações em cadeia do processo oxidativo, o ácido linoléico conjugado poderia atuar como pró-oxidante em sistemas biológicos. O fato é que, embora existam controvérsias, esse ácido graxo parece apresentar uma autoproteção à oxidação, mas o ato de consumir um ácido graxo em seu estágio inicial de autoxidação estimulou o aparecimento de estudos objetivando reinvestigar o efeito antioxidante atribuído ao ácido linoléico conjugado. Pouco tempo depois da identificação do composto em estudo muitos grupos de pesquisadores já apontavam indícios do possível efeito pró-oxidante do mesmo por meio da quantificação de produtos primários e secundários da autoxidação lipídica como, peróxidos e malondialdeído, respectivamente, de eicosanóides resultantes da oxidação pela via enzimática e não enzimática, como 15-ceto-dihidro PGF ${ }_{2 \alpha}$ e 8-iso-PGF $2 \alpha$ isoprostana, respectivamente, e da atividade biológica dos sistemas enzimáticos de proteção à oxidação, assim como, de reparo aos danos causados por tal processo como, a catalase (CAT), a glutationa peroxidase (GPx) e a superóxido dismutase (SOD) ${ }^{1-5}$.

A partir do ano 2000, muitos trabalhos, particularmente em humanos, demonstram claramente que o ácido linoléico conjugado induz a peroxidação lipídica, visto que indicadores bastante específicos da oxidação dos lípides biológicos estão significativamente aumentados após suplementação com ácido linoléico conjugado 6-10. Por outro lado, estudos comprovando a ação antioxidante desse ácido graxo são freqüentes ${ }^{11,12}$, o que aumenta ainda mais a dificuldade de estabelecer um consenso a respeito da sua ação sobre o processo de oxidação lipídica. Muitas são as variáveis a serem controladas e os estudos apresentam protocolos distintos uns dos outros quanto ao modelo experimental, ao tipo, à dose, ao tempo de suplementação e aos indicadores do estresse oxidativo e seus respectivos métodos e local de determinação. Outro efeito deletério do ácido linoléico conjugado que tem sido reportado é o acúmulo de lípides no fígado de modelos experimentais, como roedores e aves, podendo levar ao aparecimento de esteatose e esteatohepatite, cuja etiologia está relacionada com uma série de situações patológicas, dentre elas, o aumento do estresse oxidativo ${ }^{13,14}$. Levando em consideração a necessidade de esclarecimentos a respeito da identificação e do entendimento das propriedades oxidativas do ácido linoléico conjugado o objetivo deste trabalho foi avaliar a estabilidade oxidativa de duas misturas comerciais desse ácido e buscar o grau de associação entre o consumo dessas misturas por ratos Wistar saudáveis em crescimento e o conteúdo total de seus lípides hepáticos, e também alguns indicadores da oxidação lipídica.

\section{MÉ T O D O S}

Delineamento experimental: o protocolo experimental do ensaio biológico foi feito da seguinte forma: 30 ratos permaneceram em período de adaptação por 7 dias, recebendo as respectivas dietas e água potável sob o sistema de livre acesso. Após este período os animais foram divididos em 3 grupos objetivando a homogeneidade quanto ao peso corporal tanto intra quanto intergrupo. Os grupos experimentais foram divididos em: grupo $C$ (controle), que recebeu ácido linoléico $60 \%$, grupo $A E$, que recebeu AdvantEdge ${ }^{\circledast}$ CLA e grupo CO, que recebeu CLA One ${ }^{\circledR}$ Free Fatty Acid Oil. A concentração de suplemento utilizada foi de $2 \%$ em relação ao consumo diário de dieta. Os animais foram suplementados diariamente durante 6 semanas. Foram feitas as determinações de índice de peróxido hepático (produtos primários da autoxidação lipídica), substâncias reativas ao ácido tiobarbitúrico (TBARS) séricas e hepáticas (produtos secundários da autoxidação lipídica), 8-iso-PGF ${ }_{2 \alpha}$ isoprostana e atividade da catalase. O peso do fígado foi obtido e o conteúdo de lípides totais do órgão foi determinado. 
Suplementos: os suplementos utilizados foram ácido linoléico 60\% Sigma (código L 1376), as misturas comerciais de ácido linoléico conjugado $75 \%$ AdvantEdge ${ }^{\circledR}$ CLA (EAS'M , Golden/CO, USA) e 75\% CLA One ${ }^{\circledR}$ Free Fatty Acid Oil 1CLA1-FFBL-KG (Pharmanutrients, Gurnee/IL, USA).

Estabilidade oxidativa dos suplementos: foi determinada dentro de um período de 90 minutos, tempo em que os suplementos ficavam armazenados a $25^{\circ} \mathrm{C}$ e na ausência de luz, até que todos os animais fossem suplementados. Para a avaliação da estabilidade oxidativa dos suplementos foi determinado o índice de peróxido utilizando o método oficial da Association Of (AOAC) ${ }^{15} \mathrm{e}$ malondialdeído de acordo com método proposto por Sinnhuber \& Yu' ${ }^{16}$.

Animais e dietas: para a realização dos ensaios biológicos foram utilizados ratos Wistar, albinos, machos, saudáveis, recém-desmamados com idade entre 21 e 23 dias, provenientes do Centro Multidisciplinar de Investigação Biológica da Universidade Estadual de Campinas. Os animais permaneceram em gaiolas individuais de crescimento e receberam água e alimentação sob o sistema de livre acesso, sendo a temperatura e a umidade do ar controladas na faixa de $22^{\circ} \mathrm{C}$, com variação de $1^{\circ} \mathrm{C}$, e de $60 \%$ a $70 \%$, respectivamente, e em ciclo de claro/escuro de 12 horas. A dieta utilizada foi a AIN93G, elaborada conforme o American Institute of Nutrition ${ }^{17} \mathrm{com}$ concentração de proteína bruta de $12 \%{ }^{18}$. Este trabalho foi aprovado pela Comissão de Ética na Experimentação Animal (CEEA - IB/Unicamp) - Protocolo $n^{\circ}$ 564-1.

Suplementação: os animais foram suplementados por meio de entubação orogástrica utilizando seringas descartáveis de $1 \mathrm{~mL}$ e agulhas de gavagem. A quantidade de suplemento administrada era calculada a cada dois dias com base no consumo médio diário de dieta de cada grupo, sendo assim a suplementação acompanhou a ingestão de dieta normal dos ratos. Levou-se em consideração a densidade de cada suplemento para o cálculo da quantidade em mililitros, que variou de 0,25 a $0,49 \mathrm{~mL}$. Os suplementos eram aspirados pela seringa e mantidos ao abrigo da luz até o momento da administração. Os ratos eram retirados grupo a grupo da sala de experimentação, acondicionados em caixas plásticas e levados à sala em que eram suplementados. Este procedimento ocorria diariamente, no período da tarde e sempre no mesmo horário.

Determinação do índice de peróxido (produtos primários da autoxidação lipídica): para a determinação do índice de peróxidos foi necessária a extração prévia dos lípides do fígado de cada rato, a qual foi feita utilizando o método de Bligh \& Dyer ${ }^{19}$ com modificações em decorrência de particularidades da amostra. Imediatamente após a extração dos lípides realizou-se a determinação do índice de peróxido utilizando o método oficial da AOAC ${ }^{15}$. Tal procedimento é baseado na oxidação do iodo na presença de iodeto de potássio pelo peróxido presente na amostra, assumindo-se que todas as substâncias oxidantes presentes na amostra são peróxidos. Para o cálculo do índice de peróxidos foi considerada a quantidade de lipídios presente na solução clorofórmica resultante do procedimento de extração dos lipídios segundo Bligh \& Dyer ${ }^{19}$.

Determinação de malondialdeído (produto secundário da autoxidação lipídica) - valor TBA: a determinação de substâncias reativas ao ácido tiobarbitúrico (TBARS) foi feita no soro e no fígado de cada animal. O método utilizado para esta análise foi o proposto por Sinnhuber \& Yu ${ }^{16}$, que tem como princípio básico a formação de um pigmento vermelho-róseo composto por duas moléculas de ácido tiobarbitúrico e uma de malondialdeído. Os resultados foram expressos em mg de malondialdeído/kg de amostra.

Determinação de 8-iso-PGF ${ }_{2 \alpha}$ isoprostana: a determinação de 8-iso-PGF ${ }_{2 \alpha}$ isoprostana, no plasma dos ratos, foi feita por imunoensaio enzimático utilizando kit comercial Cayman Chemical catálogo número 516351 . O método baseia-se na competição entre a 8-iso-PGF $F_{2 \alpha}$ isoprostana e a 8-iso-PGF ${ }_{2 \alpha}$ isoprostana-acetilcolinesterase conjugada (marcador) por um limitado número de sítios ligadores para antisoro específico de 8-iso-PGF $2 \alpha$ 
isoprostana. Os resultados foram expressos em $\mathrm{pg} / \mathrm{mL}$ de amostra.

Determinação da atividade da catalase: para a determinação da atividade da catalase foi utilizada a metodologia descrita por Góth ${ }^{20}$, que consiste na determinação da atividade da catalase sérica por meio da reação com o peróxido de hidrogênio. Os resultados foram expressos em kU/L, considerando que uma unidade de catalase decompõe, nas condições acima descritas, $1 \mu \mathrm{mol}$ de peróxido de hidrogênio por minuto.

Análise da histologia hepática: parte do lobo esquerdo do fígado $(0,3 \times 0,5 \mathrm{~mm})$ de 4 ratos de cada grupo (controle e experimental) foi extraído e imediatamente fixado em solução de glutaraldeído (2\%) em tampão cacodilato $(0,1 \mathrm{M}$, $\mathrm{pH} 7,3$ ) durante 15 horas a $4^{\circ} \mathrm{C}$. Após esta etapa, as amostras seguiram para o processo de desidratação. Para o processo de desidratação as amostras foram lavadas 3 vezes por 15 minutos em série etanólica iniciando com etanol 50\%, seguido de $70 \%, 90 \%$, 95\% e 100\%, finalizando com duas lavagens de 10 minutos em xilol, quando as amostras foram submetidas ao processo de inclusão em parafina. Depois de incluídas em parafina as amostras foram cortadas $(3 \mu \mathrm{m}$ de espessura) e submetidas, após desparafinização

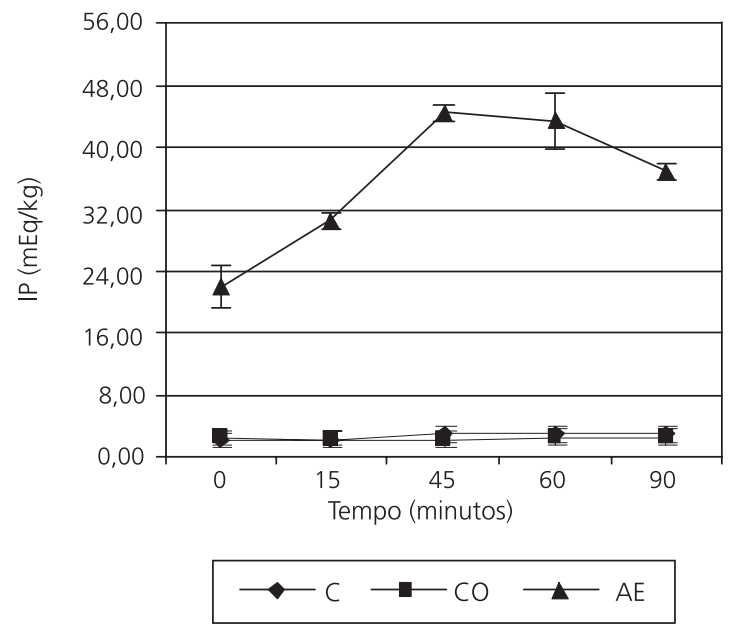

e hidratação, a coloração com Hematoxilina e Eosina ${ }^{21}$.

A associação entre o consumo de ácido linoléico conjugado e os indicadores da oxidação lipídica foi obtida pela análise de correlação linear de Pearson, considerando coeficientes moderados de correlação, positivos ou negativos, com valor de r entre 0,5 e 0,95 e entre - 0,5 e- 0,95, respectivamente. O software utilizado para a análise foi o Statistical Analysis System ${ }^{22 .}$

\section{RESULTADOS}

Pode-se dizer que a estabilidade oxidativa das misturas comerciais de ácido linoléico conjugado foi diferente entre as mesmas. As curvas que representam a produção de peróxidos e malondialdeído entre os tempos $T_{0}$ e $T_{90}$ podem ser observadas na Figura 1. Os valores de índice de peróxido (IP) foram maiores em $A E\left(T_{0}=21,87\right.$, desvio-padrão - $D P=3,57 \mathrm{mEq} / \mathrm{kg}$ e $T_{90}=37,05$, $\mathrm{DP}=1,17 \mathrm{mEq} / \mathrm{kg}$ ), quando comparados com $\mathrm{CO}$ $\left(T_{0}=2,35, D P=0,19 \mathrm{mEq} / \mathrm{kg}\right.$ e $T_{90}=2,44, D P=0,29 \mathrm{~m}$ $\mathrm{Eq} / \mathrm{kg})$ e com $C\left(T_{0}=2,03, D P=0,13 \mathrm{mEq} / \mathrm{kg}\right.$ e $T_{90}=2,83, D P=0,73 \mathrm{mEq} / \mathrm{kg}$ ). Já os valores de malondiadeído (MDA) foram maiores para $\mathrm{C}\left(\mathrm{T}_{0}=41,08\right.$, $D P=4,80 \mathrm{mg} / \mathrm{kg}$ e $\left.T_{90}=46,16, D P=2,22 \mathrm{mg} / \mathrm{kg}\right) \mathrm{em}$

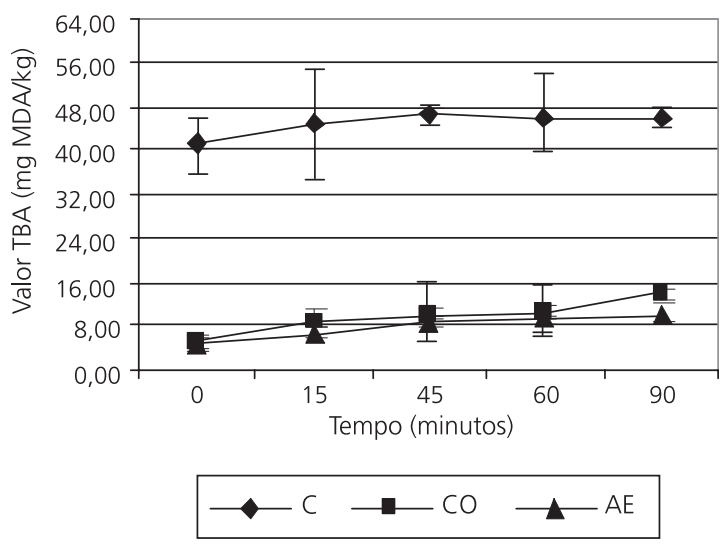

Figura 1. Curva da produção in vitro de Peróxidos (IP) e Malondialdeído (Valor TBA) das misturas comerciais de ácido linoléico conjugado (suplementos: CO e AE) e do ácido linoléico (controle: C) no intervalo de tempo entre o preparo (tempo inicial: $T_{0}$ ) e a administração por meio de entubação orogástrica nos ratos dos grupos controle e suplementados (tempo final: $\left.T_{90}\right)$. 
relação ao $A E\left(T_{0}=4,61, D P=0,04 \mathrm{mg} / \mathrm{kg}\right.$ e $\left.\mathrm{T}_{90}=9,67, \mathrm{DP}=0,14 \mathrm{mg} / \mathrm{kg}\right)$ e $\mathrm{CO}\left(\mathrm{T}_{0}=5,27\right.$, $D P=0,47 \mathrm{mg} / \mathrm{kg}$ e $T_{90}=13,75, D P=2,47 \mathrm{mg} / \mathrm{kg}$ ).

Quanto às correlações obtidas entre o consumo das misturas comerciais pelos ratos e os indicadores da oxidação dos seus lípides biológicos, foram encontrados coeficientes de correla- ção moderados, negativos e significantes entre essas variáveis e o consumo de CLA (Figura 2)

O valor médio do conteúdo lipídico total dos grupos era de $22,42 \%(D P=1,40)$. Em ensaio preliminar ao presente não foram observadas diferenças quanto ao conteúdo total de lípides hepáticos entre os grupos, cujo valor médio foi de
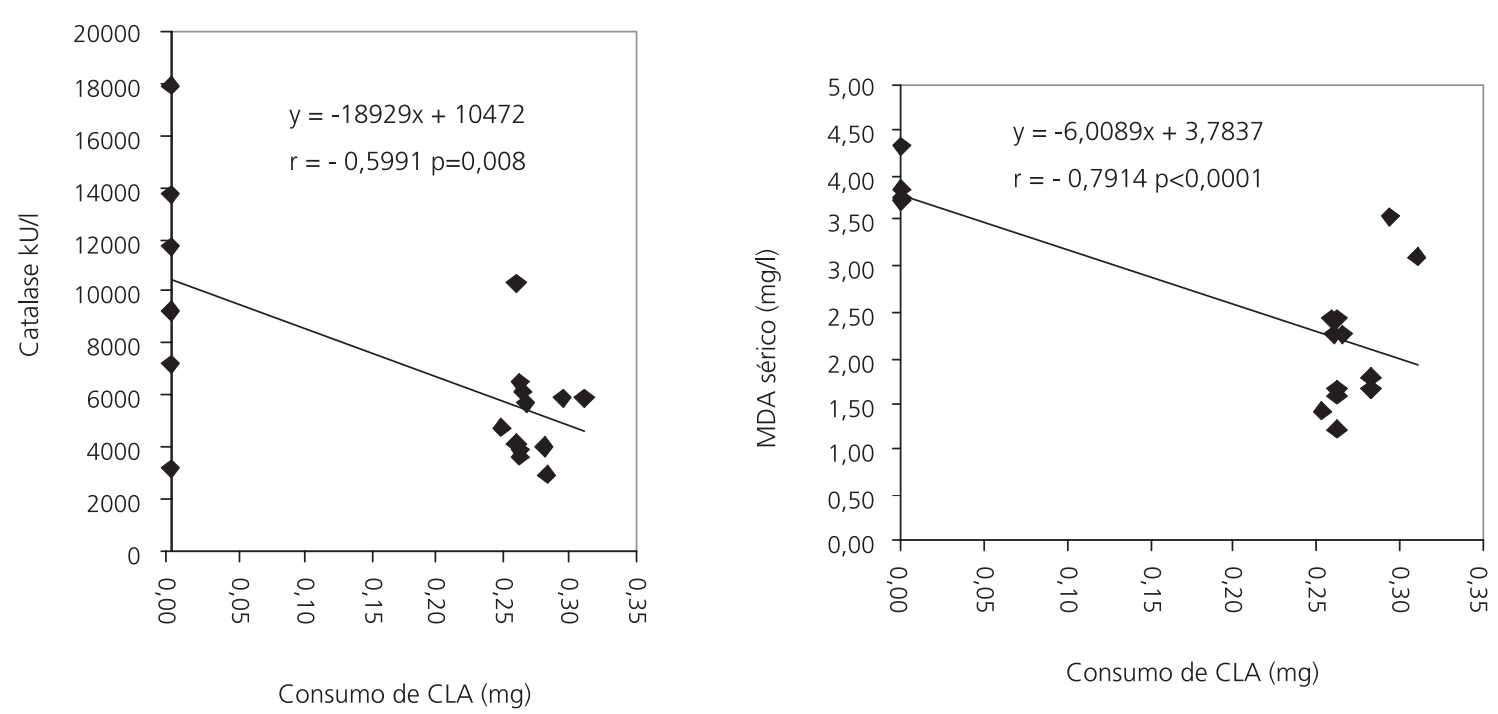

Figura 2. Correlação entre o consumo médio diário das misturas comerciais de ácido linoléico conjugado pelos ratos dos grupos controle e suplementados e a concentração sérica de malondialdeído (MDA) e atividade sérica da catalase.

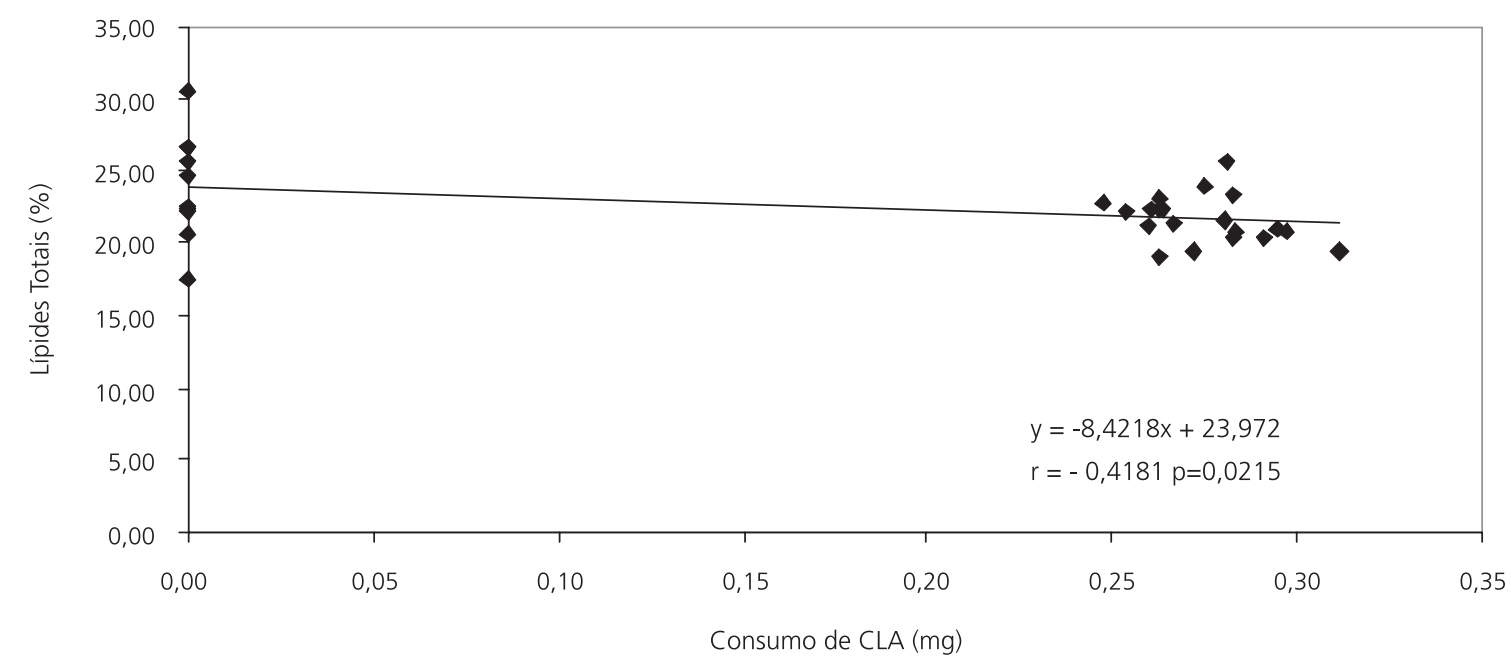

Figura 3. Correlação entre o consumo médio diário das misturas comerciais de ácido linoléico conjugado pelos ratos dos grupos controle e suplementados e a concentração de seus lípides totais hepáticos. 
$19,10 \%(D P=0,85)$. A associação entre o consumo das misturas de ácido linoléico conjugado e o conteúdo de lípides total do fígado dos animais demonstrou coeficientes negativos e baixos, porém significantes (Figura 3). No entanto, ao observar as imagens obtidas por meio de microscopia ótica, nota-se que o número de glóbulos de gorduras no fígado dos ratos que foram submetidos à suplementação com ácido linoléico conjugado, especialmente a mistura AdvantEdge ${ }^{\circledR}$ (grupo AE), é maior em número e tamanho (Figura 4).

\section{DIS CUSS Ã O}

Embora as pesquisas quanto à estabilidade oxidativa dos isômeros de ácido linoléico conjugado sejam divergentes, é comum o fato de que
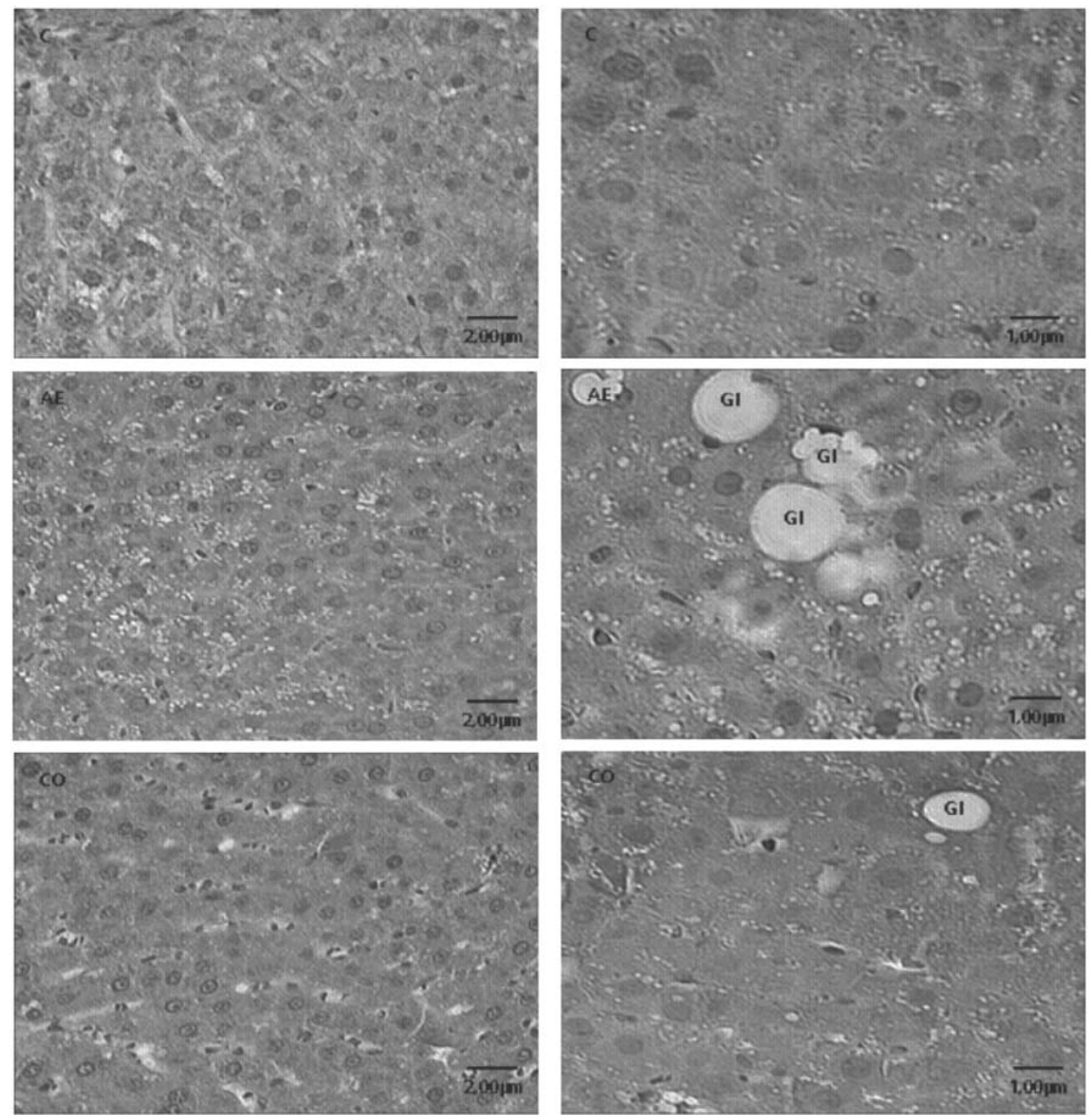

Figura 4. Imagens hepáticas obtidas por microscopia ótica de animal que recebeu durante seis semanas suplementação diária com ácido linoléico (C) e com as misturas comerciais de ácido linoléico conjugado AdvantEdge ${ }^{\circledR}(A E)$ e One ${ }^{\circledR}(C O)$.

Nota: Gl: Glóbulo de gordura. 
o CLA seja mais estável que outros ácidos graxos poliinsaturados que não tenham ligações do tipo trans. Até mesmo dentre os isômeros de CLA, aqueles que possuem ligações do tipo cis são menos estáveis à oxidação em relação aos trans. A estabilidade oxidativa do CLA também é dependente da esterificação para formar acilgliceróis, especialmente os triacilgliceróis, de forma que a estabilidade é menor quando o CLA está em sua forma livre ${ }^{23-25}$. Na presente pesquisa, embora ambas as misturas possuam seus isômeros em sua forma livre, a mistura CO foi estável à autoxidação, em comparação ao ácido linoléico. É importante ressaltar que tanto as misturas de CLA quanto o ácido linoléico foram armazenados da mesma forma e pelo mesmo tempo. Pode-se especular que a diferença de estabilidade entre as misturas tem relação com a fonte e o procedimento tecnológico que originaram os isômeros de CLA.

O início das pesquisas com ácido linoléico conjugado foi marcado pela descoberta de seu efeito anticarcinogênico, explicado pela sua ação antioxidante, especialmente do isômero cis-9, trans-11. A ação antioxidante do CLA era explicada pela formação de $\beta$-hidroxiacroleína de CLA, que, por sua vez, seria a responsável por inibir reações do tipo Fenton ${ }^{26}$. Mas, ainda na década de 90, começaram a aparecer os estudos de reinvestigação das propriedades antioxidantes do CLA baseados na hipótese de que esse ácido graxo conjugado, ou seja, um ácido graxo em seu estágio inicial de autoxidação, atuaria como agente pró-oxidante. Um importante estudo foi o de Van Den Berg et al. ' ; os autores demonstraram que o CLA não atua como antioxidante, mesmo em condições de estresse oxidativo mediadas por íons metálicos. As pesquisas apontando o CLA como pró-oxidante em sistemas biológicos aconteceram de forma mais acentuada a partir de 2000, quando os pesquisadores começaram a afirmar categoricamente que o CLA aumenta o estresse oxidativo, particularmente em humanos. Por meio da determinação de inúmeros indicadores da oxidação dos lípides biológicos diversos estudos trazem dados que confirmam a atuação do CLA como pró-oxidante ${ }^{5-10}$. No entanto, para intrigar ainda mais a comunidade científica a respeito da influência do ácido linoléico conjugado sobre o processo de oxidação dos lípides biológicos, estudos recentes demonstram a ação antioxidante do CLA, como, por exemplo, os estudos de Kim et al. ${ }^{11}$ com ratos Sprague-Dawley e de Arab et al. ${ }^{12}$ com fibroblastos humanos.

Quanto às correlações obtidas entre o consumo das misturas comerciais de ácido linoléico conjugado pelos ratos e os indicadores da oxidação dos seus lípides biológicos, pode-se dizer que esse ácido graxo conjugado poderia atuar como um agente antioxidante. Pode-se chegar a essa conclusão quando se analisam os resultados referentes à concentração sérica de malondialdeído e atividade sérica da catalase, visto que foram encontrados coeficientes de correlação moderados, negativos e significantes entre essas variáveis e o consumo de CLA (Figura 2). Estes resultados diferem daqueles obtidos por alguns pesquisadores que objetivam reexaminar as propriedades antioxidantes do CLA, os quais observam valores de malondialdeído mais altos, quando comparados aos seus respectivos grupos controles ${ }^{4-7,27}$. Utilizou-se também como indicador da oxidação dos lípides biológicos pela via não enzimática, um eicosanóide da série $\mathrm{F}$ denominado 8-iso-PGF ${ }_{2 \alpha}$ isoprostana, que é considerado indicador bastante específico para avaliar o grau de estresse oxidativo em diversos modelos experimentais $^{28}$. As correlações obtidas entre a concentração plasmática desse eicosanóide e o consumo das misturas comerciais de ácido linoléico conjugado foram positivas, embora fracas e não significantes ( $r=0,3033, p=0,2003$ ). Esse indicador tem sido muito utilizado nos trabalhos (muitos em humanos) objetivando avaliar a ação do CLA sobre a oxidação dos lípides biológicos e, na maioria dos estudos, o que se observa é o aumento da concentração do mesmo ${ }^{6-10}$. O mesmo resultado foi observado quando realizada a correlação entre a concentração de peróxidos hepáticos e o consumo de CLA ( $r=0,3747, p=0,1458)$. Ressalta-se que, embora a correlação entre consumo de 
CLA e concentração plasmática de 8-iso-PGF ${ }_{2 \alpha}$ isoprostana e hepática de peróxidos não tenha sido significante, existe uma tendência para o aumento desses indicadores após o consumo de CLA, tendência esta que, associada à gama de informações a respeito da possível ação pró-oxidante do CLA reportada pela comunidade científica, deve ser considerada como respaldo para dar continuidade às pesquisas das propriedades antioxidantes do CLA.

Além da possibilidade de aumentar a susceptibilidade dos lípides biológicos à oxidação, o ácido linoléico conjugado também tem sido apontado por alguns pesquisadores como responsável por promover acúmulo de lípides no fígado de animais, o que pode resultar em esteatose e esteatohepatite ${ }^{5,13,15}$. No presente trabalho não foram observadas diferenças significantes $(p>0,05)$ quanto ao conteúdo de lípides total hepático entre o grupo controle e os grupos que receberam AdvantEdge ${ }^{\circledR}$ CLA ou CLA One ${ }^{\circledR}$.

Apesar da observação de maior número e tamanho de glóbulos de gorduras no fígado dos animais, pode-se dizer que não houve alteração na histologia hepática. O fato de observar mais glóbulos de lípídios nos fígados dos ratos que consumiram CLA caracteriza uma informação de natureza qualitativa, no entanto não menos importante, já que permite conclusões sobre a integridade das células hepáticas. Anormalidades na morfologia hepática acompanhadas do acúmulo de lípides em animais suplementados com CLA têm sido reportadas por alguns pesquisadores $^{14,29}$, enquanto outros observam ou não o acúmulo de lípides sem alterar a morfologia do órgão ${ }^{5,30}$. Nas condições de suplementação do presente trabalho não se observou acúmulo de lípides hepáticos e tampouco alteração da morfologia do órgão dos ratos.

No que diz respeito aos mecanismos de ação pelos quais o CLA influencia o processo de oxidação lipídica, esses não foram identificados na presente pesquisa mas, de acordo com as investigações mais recentes em CLA, há fortes indícios que a ação desse ácido graxo sobre receptores nucleares denominados receptores ativados por proliferadores de peroxissoma (PPAR) seria a explicação não somente para o efeito anti/pró-oxidante, mas para todos os efeitos do CLA até hoje identificados. Um dos primeiros trabalhos que demonstrou o controle da expressão gênica pelo CLA por meio da sua ação sobre receptores nucleares específicos data do final da década de $90^{31}$. A partir de então muitos trabalhos apontam o ácido linoléico conjugado como modulador da expressão de receptores nucleares ativados por proliferadores de peroxissoma ou então como modulador da expressão de genes que estão sob o controle transcricional desses, de forma a explicar os seus efeitos fisiológicos ${ }^{31-37}$. Embora já seja de conhecimento da comunidade científica a ação do ácido linoléico conjugado sobre os receptores nucleares ativados por proliferadores de peroxissoma, ainda há muito o que investigar a respeito da modulação da expressão gênica induzida por esse ácido graxo de forma a explicar suas ações benéficas e até mesmo seus efeitos adversos. Acredita-se que a biologia molecular moderna contribua de forma significativa na obtenção dessas explicações para estabelecer um consenso a respeito da utilização do ácido linoléico conjugado como um coadjuvante na prevenção e no tratamento de diversas doenças metabólicas. Há que considerar, como perspectiva de continuidade da pesquisa, a tendência para a elevação de 8-iso-PGF ${ }_{2 \alpha}$ isoprostana plasmática e de peróxidos hepáticos, cujo aumento induzido pelo ácido linoléico conjugado é bastante reportado na literatura.

\section{O N C L U S Ã O}

Pode-se concluir que a estabilidade à autoxidação das misturas comerciais de CLA foi diferente, tendo a mistura $\mathrm{CO}$ se apresentado bastante estável em comparação ao ácido linoléico. Quanto à influência das misturas de CLA sobre a oxidação dos lípides biológicos, pode-se dizer que foi reduzida, vistos os coeficientes das correlações entre a suplementação e a concentração sérica de malondialdeído e atividade sérica da catalase. 
O conteúdo dos lípides hepáticos não aumentou após o consumo dos suplementos. Embora se tenha observado, por meio de microscopia ótica, um aumento qualitativo dos glóbulos de lipídios em comparação ao controle, não houve alteração da morfologia do órgão. Por fim, as perspectivas de continuidade da presente pesquisa são de aprofundamento das investigações sobre a ação do ácido linoléico conjugado no sentido de reforçar as investigações brasileiras sobre o tema em questão e tornar disponível para a população, com o respaldo da legislação vigente, um produto seguro que, futuramente, possa ser utilizado como coadjuvante na prevenção e no controle da obesidade e de doenças a ela associadas.

\section{A GRADECIMENTOS}

À Fundação de Amparo à Pesquisa do Estado de São Paulo (Processo 2003/07648-4); ao Conselho Nacional de Desenvolvimento Científico e Tecnológico (Processo 133874/2003-6), pelo apoio financeiro à Pesquisa e à pesquisadora A.P. BOTELHO, respectivamente. À Sra. Yara Fagnani Honório, do Laboratório de Microscopia de Alimentos da Faculdade de Engenharia de Alimentos, e à Dra Elisângela Faria, do Laboratório de produtos Naturais do Instituto de Biologia da Universidade Estadual de Campinas, pela assistência técnica.

\section{$C O L A B O R A C ̧ \tilde{A} O$}

L.F. SANTOS-ZAGO, A.P. BOTELHO e A.C. OLIVEIRA participaram da elaboração do Projeto de Pesquisa, da tabulação e da discussão dos resultados e da elaboração do Artigo.

\section{REFER Ê N CIAS}

1. Van Den Berg JJM, Cook NE, Tribble DL. Reinvestigation of the antioxidant properties of conjugated linoleic acid. Lipids. 1995; 30(5)599-605.

2. Cantwell H, Devery R, Stanton C, Lawless F. The effect of a conjugated linoleic acid on superoxide dismutase, catalase and glutathione peroxidase in oxidatively-challenged liver cells. Biochem Soc T. 1998; 26(1):52.
3. Banni S, Angioni E, Contini MS, Carta G, Casu V, lengo $\mathrm{GA}$, et al. Conjugated linoleic acid and oxidative stress. J Am Oil Chem Soc. 1998; 75(2):261-67.

4. Cantwell H, Devery R, O'shea M, Stanton C. The effect of conjugated linoleic acid on the antioxidant enzyme defense system in rat hepatocytes. Lipids. 1999; 34(8):833-39.

5. Yamasaki M, Mansho K, Mishima H, Kimura G, Sasaki M, Kasai M, et al. Effect of dietary conjugated linoleic acid on lipid peroxidation and histological change in rat liver tissues. J Agr Food Chem. 2000; 48(12):6367-71.

6. Basu S, Risérus U, Turpein A, Vessby B. Conjugated linoleic acid induces lipid peroxidation in men with abdominal obesity. Clin Sci. 2000; 99(6):511-16.

7. Basu S, Smedman A, Vessby B. Conjugated linoleic acid induces lipid peroxidation in humans. FEBS Letters. 2000; 468(1):33-36.

8. Risérus U, Basu S, Jovinge S, Fredrikson GN, Ärnlöv J, Vessby B. Supplementation with conjugated linoleic acid causes isomer-dependent oxidative stress and elevated C-reactive protein. Circulation. 2002; 106(15):1925-29.

9. Risérus U, Vessby B, Ärnlöv J, Basu S. Effects of cis-9, trans-11 conjugated linoleic acid supplementation on insulin sensitivity, lipid peroxidation, and proinflammatory markers in obese men. Am J Clin Nutr. 2004; 80(2):279-83.

10. Smedman A, Vessby B, Basu S. Isomer-specific effects of conjugated linoleic acid on lipid peroxidation in humans: regulation by $\alpha$-tocopherol and cyclo-oxygenase-2 inhibitor. Clin Sci. 2004; 106(1):67-73.

11. Kim JH, Hubbard NE, Ziboh V, Erickson KL. Attenuation of breast tumor cell growth by conjugated linoleic acid via inhibition of 5 -lipoxygenase activating protein. Biochim Biophys Acta. 2005; 1736(3):244-50.

12. Arab K, Rossary A, Soulère L, Steghens JP. Conjugated linoleic acid, unlike other unsaturated fatty acids, strongly induces glutathione synthesis without any lipoperoxidation. Brit J Nutr. 2006; 96(5):811-19.

13. Belury MA, Kempa-Steczko A. Conjugated linoleic acid modulates hepatic lipid composition in mice. Lipids. 1997; 32(2):199-204.

14. Cherian G, Holsonbake TB, Goeger MP, Bildfell R. Dietary CLA alters yolk and tissue FA composition and hepatic histopathology of laying hens. Lipids 2002; 37(8):751-7.

15. Association of Official Analytical Chemists. Official methods of analysis. 16th ed. Virgínia: AOAC International; 1995. v.1. 
16. Sinnhuber RO, Yu TC. 2-Thiobarbituric acid method for the measurement of rancidity in fishery products. II. The quantitative determination of malonaldehyde. Food Technol. 1958; 12(1):9-12.

17. Reeves PG, Nielsen FH, Fahey GCJ. AIN-93 Purified diets for laboratory rodents: final report of the American Institute of Nutrition ad hoc Writing Committee on the Reformulation of the AIN-76A rodent diet. J Nutr. 1993; 123(11):1939-51.

18. Goena M, Mazo F, Fernández-González L, Tosar A, Fruhbeck $\mathrm{G}$, Santidrián $\mathrm{S}$. Effect of the raw legume Vicia ervilha on muscle and liver protein metabolism in growing rats. Rev Española Fisiol. 1989; 45:55-60.

19. Bligh EG, Dyer WJ. A rapid method of total lipid extration and purification. Can J Biochem Physiol. 1959; 37(8):911-7.

20. Goth L. A simple method for determination of serum catalase activity and revision of reference range. Clin Chim Acta. 1991; 196(2-3):143-52.

21. Behmer OA, Tolosa EMC, Neto AGF. Manual de técnicas para histologia normal e patológica. São Paulo: Edart Editora; 1976.

22. SAS Institute Project for Windows: user's guide statistics. Version 8.0. Cary (USA); 2003.

23. Yang L, Leung LK, Huang $Y$, Chen ZY. Oxidative stability of conjugated linoleic acid isomers. J Agric Food Chem. 2000; 48(8):3072-76.

24. Tsuzuki T, Igarashi M, Iwata T, Ymauchi-Sato $Y$, Yamamoto $\mathrm{T}$, Ogita $\mathrm{K}$, et al. Oxidation rate of conjugated linoleic acid and conjugated linolenic acid is slowed by triacylglycerol esterification and a-tocopherol. Lipids. 2004; 39(5):475-80.

25. Miyazawa T, Tsuzuki T, Nakagawa K, Igarashi M. Fatty acids with conjugated unsaturation: relationship between oxidative stability and physiological activities. Lipid Technol. 2005; 17(10): 221-5.

26. Ha YL, Storkson J, Pariza M. Inhibition of benzo(a)pyrene-induced mouse forestomach neoplasia by conjugated linoleic acid. Cancer Res. 1990; 50(4):1097-101.

27. Flintoff-Dye NL, Omaye ST. Antioxidant effects of conjugated linoleic acid isomers in isolated human low-density lipoproteins. Nutr Res. 2005; 25(4): $1-12$

28. Roberts LJ, Morrow JD. Measurement of F2-isoprostanes as an index of oxidative stress in vivo. Free Radical Bio Med 2000; 28(1):505-13.
29. Cherian G, Goeger MP. Hepatic lipid characteristics and histopathology of laying hens fed CLA or n-3 fatty acids. Lipids. 2004; 39(4):31-6.

30. Macarulla MT, Fernández-Quintela A, Zabala A, Navarro V, Echevarría E, Churruca l, et al. Effects of conjugated linoleic acid on liver composition and fatty acid oxidation are isomer-dependent in hamster. Nutrition. 2005; 21(1):512-9.

31. Moya-Camarena SY, Vanden Heuvel JP, Blanchard SG, Leesnitzer LA, Belury MA. Conjugated linoleic acid is a potent naturally occurring ligand and activator of PPARa. J Lipid Res. 1999; 40(4): 1426-33.

32. Choi YJ, Kim YC, Han YB, Park Y, Pariza MW, Ntambi JM. The trans-10, cis-12 isomer of conjugated linoleic acid downregulated stearoyl-CoA desaturase gene expression in 3T3-L1 adipocytes. J Nutr. 2000; 130(8):1920-24.

33. Belury MA, Moya-Camarena SY, Lu M, Shi L, Leesnitzer LM, Blanchard SG. Conjugated linoleic acid is na activator and ligand for peroxissome proliferator-activated receptor-gama (PPARg). Nutr Res. 2002; 22(7):817-24.

34. Kang K, Liu W, Albright KJ, Park Y, Pariza MW. Trans10, cis-12 inhibits differentiation of 3T3-L1 adipocytes and decrases PPAR gamma expression. Biochem Bioph Res Co. 2003; 303(3):795-9.

35. Cimini AM, Cristiano L, Colafarina S, Benedetti E, Di Loreto S, Festuccia C, et al. PPARg-dependent effects of conjugated linoleic acido in the human glioblastoma cell line (ADF). Int J Cancer. 2005; 117(6):923-33.

36. Bassaganya-Riera J, Hontecillas R. CLA and n-3 PUFA differentially modulate clinical activity and colonic PPAR-responsive gene expression in a pig model of experimental IBD. Clin Nutr. 2006; 25(3): 454-65.

37. Ringseis R, Müller A, Herter C, Gahler S, Steinhart $H$, Eder K. CLA isomers inhibit TNFa-induced eicosanoid release from human vascular smooth muscle cells via a PPARg ligand-like action. Biochim Bioph Acta. 2006; 1760(2):290-300.

Recebido em: 11/5/2007

Versão final reapresentada em: 18/7/2008

Aprovado em: 8/9/2008 
